\title{
Message from the new Editor-in-Chief
}

\section{Longqin (Long) $\mathrm{Hu}^{1}$}

Published online: 13 January 2020

(c) Springer Science+Business Media, LLC, part of Springer Nature 2020
Drs Paulo Carvalho (University of the Incarnate Word), Young Kim (Bluefield State College), and Anand Sridhar (Massachusetts College of Pharmacy and Health Sciences), who have all agreed to continue to serve as Associate Editors. As I work to recruit new members to our Editorial Board, the current team of Senior and Associate Editors will be sufficient to ensure a smooth transition and continuity at $M C R$.

My vision is for $M C R$ to become one of the top journals publishing exciting research in medicinal chemistry, broadly defined. In keeping with previously established goals of $M C R$ as "an international journal for rapid communications on design and mechanisms of action of biologically active agents", we will strive to publish cutting edge research in medicinal chemistry and early drug discovery from all over the world. To increase the impact of $M C R$ and to help our readers stay on top of their topic areas, we will strategically invite submissions of timely critical review articles from authors who have made significant contributions in the areas they write and review. We will also start soliciting manuscripts for thematic issues and special issues in honor of well-known medicinal chemists who have devoted their careers to advancing medicinal chemistry research. As I learn the ropes of managing the journal, I sincerely welcome any recommendations and suggestions to make $M C R$ a better and more impactful journal in the field of medicinal chemistry.

Finally, I want to thank Springer Nature for entrusting me with the responsibilities and the honor of serving as the Editor-in-Chief of $M C R$.
Longqin (Long) $\mathrm{Hu}$

LongHu@pharmacy.rutgers.edu

1 Ernest Mario School of Pharmacy, Rutgers, The State University of New Jersey, 160 Frelinghuysen Road, Piscataway, NJ 08854, USA 